\title{
Serum Insulin-like Growth Factor Binding Protein-6 (IGFBP-6) Levels in Various Clinical Conditions
}

Izumi Fukuda, Naomi Hizuka, Kazue Takano, Kumiko Asakawa-Yasumoto, Yumiko Okubo, Tomoko Suzuki, Chika Shimojoh, Kazuo Shizume and Hiroshi Demura

Department of Medicine, Institute of Clinical Endocrinology, Tokyo Women's Medical College (IF, NH, KT, $K A-Y, Y O, T S, H D)$ and Research Institute, The Foundation for Growth Science (CS, KS), Tokyo, Japan

\section{Introduction}

There are few reports on serum levels of insulin-like growth factor binding protein- 6 (IGFBP-6) (1). Recently we have developed Western immunoblot of IGFBP-6. In the present study, to investigate the clinical significance and regulation of serum IGFBP-6, we measured serum IGFBP-6 in various clinical conditions by Western immunoblot.

\section{Materials and Methods}

\section{Serum and Urine Samples}

Serum samples were obtained from normal subjects, patients with growth hormone deficiency (GHD), acromegaly, and chronic renal failure (CRF). To investigate the effects of IGF-I on serum IGFBP-6, we measured serum IGFBP-6 in normal subjects who received $\mathrm{sc}$ administration of IGF-I (0.1 $\mathrm{mg} / \mathrm{kg}$ ) once a day for 7 consecutive days (2). Spot urine samples were collected from two normal adults; $20 \mathrm{~mL}$ urine samples were dialyzed against distilled water overnight and lyophilized. The samples were reconstituted with distilled water and then passed through

Correspondence: Dr. Izumi Fukuda Department of Medicine, Institute of Clinical Endocrinology, Tokyo Women's Medical College, 8-1, Kawada-cho, Shinjuku-ku, Tokyo 162 Japan a desalting column (AmpureTM SA). The desalted samples were used for IGFBP-6 Western immunoblot.

\section{Western Immunoblot for IGFBP-6}

Serum or urine samples were electrophoresed on $12 \%$ SDS-acrylamide gel under non reducing conditions. The size-fractionated proteins were electroblotted onto a nitrocellulose sheet. The sheet was incubated with anti-IGFBP-6 antibody (Austral Biologicals, CA), washed, and then incubated with horse raddish peroxidase-conjugated anti-rabbit IgG. IGFBP-6-anti-IGFBP-6 antibody complexes were detected with Enhanced Chemiluminescence (ECL) system.

\section{Results}

\section{Serum IGFBP-6 Values}

Immunoreactive band of IGFBP-6 in normal serum was recognized at $30 \mathrm{kDa}$, and the band was displaced by unlabeled IGFBP- 6 . Therefore, specific IGFBP-6 in serum was detected in this system.

\section{Effects of GH or IGF-I on Serum IGFBP-6}

Using this system, IGFBP-6 in sera from patients with GHD, acromegaly, and from 
normal subjects who received IGF-I for 7 consecutive days were studied to investigate whether GH or IGF-I regulate serum IGFBP6 levels or not.

When sera from patients with GHD were studied, serum IGFBP-6 did not change before and after GH treatment. Furthermore, serum IGFBP-6 levels did not change after successive adenomectomy in patients with acromegaly and after repetitive IGF-I administration for 7 days in normal adults.

\section{IGFBP-6 Values in Various Clinical}

\section{Conditions}

Compared with the other clinical conditions studied, serum IGFBP-6 levels were remarkably elevated in patients with CRF.

Next we investigated whether increased levels of IGFBP-6 in patients with CRF change either after hemodialysis or renal transplantation. However, the levels did not change after hemodialysis. However, serum IGFBP-6 levels decreased one day after renal transplantation and decreased further with the improvement in renal function.

\section{Urinary IGFBP-6}

IGFBP-6 in urine from normal subjects was studied as we speculated that increased IGFBP-6 levels in CRF might be related to the retention of IGFBP- 6 in serum. IGFBP-6 was detected in normal urine samples.

\section{Discussion}

In this study, IGFBP-6 values in serum and urine samples were measured using IGFBP-6 Western immunoblot.
1) Immunoreactive IGFBP-6 was detected at $30 \mathrm{kDa}$ in serum and urine using this system.

2) Serum IGFBP-6 levels were not GH nor IGF-I dependent.

3) Serum. IGFBP-6 levels remarkably increased in patients with chronic renal failure and the levels did not change after hemodialysis. However, the IGFBP-6 levels dramatically decreased already one day after renal transplantation, and decreased further with the improvement of renal function.

These data indicate that IGFBP-6 might be excreted by the kidneys and serum IGFBP6 levels might be related to renal function.

\section{References}

1. Baxter RC, Saunders H. Radio-immunoassay of insulin-like growth factor-binding protein- 6 in human serum and other body fluids. J Endocrinol 1992; 134: 133-9.

2. Takano K, Hizuka N, Shizume K, Asakawa K, Fukuda I, Demura H. Repeated sc administration of recombinant human insulin-like growth factor I (IGF-I) to human subjects for 7 days. Growth Regul 1991; 1: 23-8. 